\title{
Application of the WHO Method of Workload Indicators of Staffing Needs to Evaluate Health Workers Availability and Capacity for Universal Health Coverage in Maternal and Child Health in Benin
}

\author{
Sossou Justin Adanmavokin*, Sossou Gilles Armand, Igué Babatounde Charlemagne, \\ Ouendo Edgard-Marius
}

Regional Institute of Public Health, Comlan Alfred Quenum Ouidah, Benin

Received May 13, 2020; Revised July 3, 2020; Accepted July 20, 2020

Copyright $\odot 2020$ by authors, all rights reserved. Authors agree that this article remains permanently open access under the terms of the Creative Commons Attribution License 4.0 International License

\begin{abstract}
To assess the operational capacity of human resources in maternal and child health services, in order to provide equitable and sustainable universal health coverage in Benin, the Workload Indicators of Staffing Need (WISN) study was conducted. Method: A total of 487 health facilities and public hospitals were sampled, representing $75 \%$ of the public health facilities. Health professionals involved in maternal and child health care were exhaustively included. Results: Overall, 487 health facilities with 3,870 human resources of all categories were evaluated for their workloads. The analysis shows that the country does not have the necessary manpower to handle the workload. The time spent by the health professional on activities changes according to the type of activity. Finally, it is noted that there is work pressure on health professionals which changes according to the type of activity. Discussion: The shortage situation leads to inequity in the distribution of human resources and is a reason for allocative and technical inefficiency. It is observed that qualified human resources devote little working time to the main activities, which explains the observed high morbidity and mortality rates, particularly for mothers and children. In conclusion, the analysis of the results shows that the pressure of work is greater in rural areas than in urban areas for the professional categories most encountered in rural areas and that the health system is fragile in the country.
\end{abstract}

Keywords WISN, Labor Pressure, Equity, Maternal and Child Health, Universal Health Coverage, Availability of Human Resources for Health, Benin Republic

\section{Introduction}

Like most countries in sub-Saharan Africa, the Republic of Benin is characterized by a high mortality rate. Specifically, the probability of dying between the ages of 15 and 50 is $111 \%$ for women and $153 \%$ for men; maternal mortality is 391 deaths per 100,000 live births; child mortality is $96 \%$, infant mortality is $55 \%$, and neonatal mortality is $30 \%$ [ [1].

Health statistics for the year 2017, in Benin, mention that the ratio number of doctors per population is 1.5 per 10,000 inhabitants, the ratio number of nurses per population is 2.4 per 5,000 inhabitants and that of midwives is 5.7 per 5,000 women of childbearing age [2]. An assessment of the coverage of qualified human resource needs (doctors, nurses, and midwives) gives a ratio number of 4.76 per 10,000 inhabitants against 25 recommended by the WHO. A review of the survey results conducted on the availability and operational capacity of health services [3] reveals that the country is exposed to a low operational capacity of maternal and child health services (MCH). Among other things, it is observed that only $38 \%$ of the human resources are trained for an optimal capacity of antenatal care, and basic obstetric and neonatal care services and $62 \%$ of the agents are trained for child immunization services.

An analysis of the health system, with a view to universal health coverage (UHC), reveals a certain fragility at the level of various pillars of the system, particularly related to the management of human resources in health [4]. These weaknesses in human resources are further worsened by the implementation of Decree No. 2018-342 of 25 July 2018 suspending the issuance of authorizations and revoking authorizations for the private practice of the medical or paramedical professions by a civil servant or 
contractual public servant and measures pertaining to the closure of illegal private practices. An evaluation of the private health sector in 2013 indicates that only $12 \%$ of the private health facilities had a license to provide health care and services [5].

Moreover, the work of the Technical Commission on Health Sector Reforms noted that $54 \%$ of the demand for health care in Benin is captured by the private sector [4]. The diagnosis carried out by the commission set up by the new government in 2016 has revealed, among other things, almost non-existent governance in the sector, poor distribution and disastrous management of resources (human, material and financial), an almost total absence of a regulatory authority for the exercise of the health profession, an absence of a policy for training and recruiting specialists, an absence of a policy to encourage the exercise of the profession in deprived areas [4]. Thus, the first consequence of various measures in reform of the health system will be to return a large proportion of private health care who does not have a legal existence to public health facilities. All this will lead to an increase in demand for health care services and the workload in public health care facilities. This increase will be further accentuated with the implementation of the UHC component of the "Insurance for Human Capital Development (ARCH)" project due to the removal of financial barriers to the use of health services. The ARCH project is an initiative of the government of the Benin Republic aimed at implementing its social protection policy, which covers health insurance, retirement for actors in the informal sector, promotion of micro-credit, and training for the poor. For the health insurance component, the State provides full coverage of health insurance for the extremely poor people and partial coverage for the non-extreme poor population [6].

The problem that emerges from the densities of health personnel is that of an under-staffing of health workers in Benin's public health sector. In turn, an insufficient number of health workers increases the workload. The increase in the workload per active agent will result in a deterioration in the quality of health services and care in the public health sector. In this context of a shortage of health professionals, the implementation of Universal Health Coverage (UHC) will result in the collapse of the health system. Indeed, with the UHC, the demand for health services and care will increase as the number of health professionals is reduced because of the measures mentioned above. By removing the financial barriers that prevented the population from using health services and care, the UHC will contribute to an increase in demand and, in turn, longer waiting times for consultation appointments and access to health services and care.

The objective of this study is to "evaluate health workers' availability and capacity for universal health coverage in maternal and child health in Benin, using the method of Workload Indicators of Staffing Needs (WISN). Developed by Peter J. Shipp for the WHO in 1998 [7], the
WISN method is a tool for managing and planning human resources for health. It is used to determine the number of health workers needed to meet the workload of a health facility and assess the workload pressure on health workers [8]. The WISN method produces information and indicates how it can be used by decision-makers in health facilities to optimize the current and future management of the human resources for health in their care [7]. It helps to assess the distribution of staff between the types of establishments at the same level of the health pyramid, in order to identify over or under-staffing in terms of workload and to estimate the size of the deficit or surplus [9].

The WISN method has already been proven in India to calculate the number of human resources needed to achieve universal coverage of maternal and child health care [10]. It was also used to estimate nursing needs and provide a description of the imbalances in Burdwan Rural Hospital in India [11]. The evaluation of the workload carried out in Uganda using the same method showed that the health facilities involved in the study had fewer nurses, midwives, and doctors than required, resulting in high work pressures, while all the facilities visited were overstaffed for nursing auxiliaries [12]. In Tanzania, researchers hypothesized that the availability of qualified human resources plays a determining role in the problem of maternal and perinatal morbidity and mortality, a WISN evaluation was carried out in sixteen (16) health facilities in Dar Es Salaam [13]. According to the results of this evaluation, there was a huge workload pressure on perinatal care in the institutions studied. A study conducted in Kenya using the WISN method at the community health care level found two results: first, the study revealed a shortage of health extension workers with a WISN ratio of 0.27 and community health workers with a WISN ratio of 0.74 ; second, the study showed that community health workers were under greater workload pressure than health extension workers [14]. Another study carried out with the WISN method in Niger and Burkina Faso found that the complementary measures increased the rate of use of health services and care, which, in turn, resulted in an overload of work for Health workers in both of the countries [15]. Moreover, the study revealed that the structures involved in the study in Niger did not have enough staff to cover the workload [15]. Another use of the WISN method in Xicheng in Beijing revealed the need for skilled human resources to cover community health care and to set time standards for community health activities [16]. Similar work in Papua New Guinea identified the main components of a health care provider's work, estimated the time needed to meet them, and defined standards for skilled health human resources [17]. Work carried out in Latin America has shown the relevance of using the WISN method to identify the components of the workload of nursing professionals and to define human resource standards for universal health 
coverage [18]. The use of WISN at Mityana General Hospital in Uganda revealed a shortage of skilled human resources and revealed that non-core activities contributed to high work pressure in all units of the hospital, thus undermining the quality of services [19]. Work carried out at Laco Hospital in Uganda has shown that the WISN method can be used to assess situations of overstaffing and understaffing and also determine not only the work pressure on nursing staff, but also provide a basis for optimal management of human resources for quality health service delivery [20]. Finally, the application of the WISN method in Namibia has made it possible to highlight the lack of qualified health workers and the inequalities observed in their distribution and also note that the shortage is more serious at the level of doctors and pharmacists while nurses are slightly overstaffed [21].

Overall, these various studies confirmed the more structured and rational approach in identifying and planning health workers needs developed by Peter J. Shipp. This approach differs from the traditional approach based on the calculation of the ratio of health personnel to population to be covered. These studies have also shown the extent to which the WISN should be used for planning health workers needs and for determining the work pressure on health professionals in health facilities.

\section{Materials and Methods}

\subsection{Type, Period, Setting, and Population of the Study}

This was a cross-sectional, descriptive, and analytical study that took place from November 2018 to August 2019. The framework of the study is the Benin Republic, a country located in West Africa with a surface area of 114,763 square kilometers and an estimated population of $11,554,473$ inhabitants, according to the 2018 projections [22]. The objective of the study was to evaluate the operational capacity of human health resources of maternal and child health services $(\mathrm{MCH})$ to offer an equitable and sustainable UHC in Benin, the study population is composed of two targets: primary and secondary. Health workers are the primary target. These are general practitioners in a health centre, or a hospital, paediatricians, gynaecologists, surgeons, internists, anaesthetists, nurses, midwives, and health care assistants. They are responsible for caring for patients by the delegation of authority from the health facilities to which they belong through employment contracts. Thus, the health facilities are the secondary target, capable, through the management and organizational decisions, of encouraging health workers to be more productive.

\subsection{Study Data}

The data used in this study comes from the database of health facilities contained in the "District Health Information Software 2" (DHIS2) for the year 2018.
DHIS2 2018 was used as the sampling frame. In DHSI2 2018, health facilities (secondary target) were recorded by department, by type of facility, and by the practice setting (rural, urban). Thus, Benin has 780 public health facilities, including 42 hospitals. The pyramidal structure of Benin's health system means that the secondary target can be broken down into two categories: first contact and reference health facilities. The distribution of health centers by area of activity shows that $83 \%$ of the centers are located and operate in rural areas, while $17 \%$ operate in urban areas.

\subsubsection{Sampling}

\section{Selection of first-contact health facilities}

Two selection rules have been defined for first-contact health centers. The first is related to the public status of the health facility and the second rule is related to the activity rate of each health facility, which consists of having carried out at least four interventions per day, i.e. 1,240 interventions per year. All types of facilities are represented (isolated dispensaries, isolated maternity units, commune health facilities). The services selected for the workload study are dispensary and maternity in the first contact health centers. In association with the two previous criteria in choice of first-contact health facilities, the criterion of the number of health center staff was specifically selected. Thus, in the Littoral department, which is a center of concentration of qualified human resources for health, all the health facilities operating in the department were systematically selected.

\section{Selection of reference health facilities}

For the choice of the reference health facilities, the exhaustiveness rule was used. Thus, the twenty (20) functional public district hospitals that constitute the first level of reference were systematically selected, the six (6) functional departmental hospital facilities (CHD) that constitute the second level of reference were systematically selected and the two university hospital centers that constitute the tertiary level of reference were also systematically selected. At the level of these reference facilities, the maternal and child health care services, in particular, the medical, paediatric, gynaecological and surgical services and the emergency departments were selected.

The criterion of the activity rate of first-contact health center

For the selection of first-contact health facilities, we used a probabilistic method with a stratified technique. A simple random selection of $75 \%$ of the health facilities in both rural and urban areas, that carry out at least 1,240 interventions per year, was done. Once the choice of facilities was made, at the level of peripheral health facilities, all the health professionals who worked there were selected with their workload. At the level of district hospitals, the Departmental Hospital facilities (CHD) of 
the Mother and Child Lagoon Hospital (HOMEL) and the Hubert K. Maga National University Hospital Centre (CNHU H.K.M), all the health professionals who work in $\mathrm{MCHs}$ were selected with their workload.

In fact, it emerged from surveys of health facilities that some facilities have a total of less than four interventions per day. In the context of this study, the notion of "intervention" refers to the actions that the health professional can perform on the user of health services. These acts include consultations, curative care, prenatal consultations, deliveries, postnatal consultations, and other activities. On the basis of this indicator of the level of activity of health facilities, health centers with an activity rate of less than four per day were excluded from the sample. Annual projections show that health facilities with less than four interventions per day have an activity rate of less than 1,240 interventions per year. Data from DHIS2 in 2018 show that 131 health facilities in Benin do not carry out at least four interventions per day, i.e. $16.79 \%$ of the health facilities. Thus, it emerges that out of a total of 780 public health facilities, 649 have an activity rate of more than four interventions per day and therefore, relevant to this study.

\section{Selection of health workers}

For the selection of health workers, we used two approaches that take into account the level of the health pyramid. The first approach consists of taking the level of the first-contact health facilities (dispensary/maternity clinic or dispensary and maternity clinic) selected in the first stratum, all the health personnel (health assistant at the dispensary, maternity assistant, nurse at the dispensary and midwife at the maternity clinic) that are there, and to record the amount of work carried out by each category of professional during the year 2018 . The choice is motivated by the fact that the quality of health services and care offered at the first contact determines the use of the first referral and the need to act in time to avoid the three delays in $\mathrm{MCH}$ defined by Thaddeus S., Maine D [23]. The second approach consists of taking health professionals from the district hospital, the CHD, the Mother and Child Lagoon Hospital and the CNHU H.K.M., who intervene in the care of $\mathrm{MCH}$. These are general practitioners in the hospital, specialist practitioners in surgery, gynecology and pediatrics, specialist internist practitioners, and midwives in the maternity ward.

\subsubsection{Sample size}

In order to have a projection very close to the real situation of the staffing needs of all the health facilities, it was decided to sample $75 \%$ of the 649 health facilities with an activity rate higher than four (4) interventions per day, i.e. 1240 interventions per year. Taking into account the selection criteria presented above, 487 selected health facilities were divided into 459 first contact health facilities, 20 district hospitals, six CHDs, and two university hospitals.

\subsubsection{Data collection techniques and tools}

Data collection was carried out using the WISN method, a human resources management tool. The WISN method makes it possible to determine the number of health workers, of a certain type, needed to cope with the workload of a given health facility and help assess the workload pressure of the health workers in the facility in question. The collection focused on quantitative data available through the health information system and workload data. Two sources of data were used to complete the tool: primary sources consisting of registers B1, B5a, B11, C6, C7, A12 used in the framework of data collection from the national health information and management system (SNIGS) and secondary sources that took into account the data collected in the DHIS 2 database. In addition, for workload data, the collection technique used was semi-structured interviews to identify, according to the occupational health category, workload components, tasks, staff salaries, activity standards, and data sources. Activity standards sheets, questionnaires, the remuneration grid for categories of human resources, and the calculation sheet for the available working time were used. A team of 34 pairs of interviewers covered the 34 health districts in Benin over a period of ten days.

\subsection{Data Analysis}

As part of the database audit, a reconciliation was made with the 2018 health workforce statements. To ensure the quality of the data collected, primary data sources were triangulated with DHIS2. Based on the specific reports of each health facility generated by the WISN tool, an Excel database was developed in order to be able to assess the situation of ratios and gaps by health districts, by the department and at national level. Data entry in the WISN tool allowed automatic calculation of the required workforce by professional category and by a health facility, the differences or gaps, the WISN ratio, and the salary costs. The criteria for interpreting the results can be summarized as follows: for differences, when the difference is greater than 0 , there is a shortage; when the difference is less than 0 , there is a surplus; and when the difference is equal to 0 , there is a balance. However, the WISN ratio is equal to the quotient of the available workforce to the required workforce. When the ratio is 0 , there is no available staff; when the ratio is between 0 and 1 , there is a high workload pressure; when the ratio is 1 , there is equilibrium; and there is a normal situation and when the ratio is greater than 1, there is no workload pressure [7].

The conceptual framework below highlights the different modalities of results that WISN can generate. The ideal trend to look for in the application of the WISN tool is for the workforce to be at equilibrium, in harmony with the workload, with good management of working time. 


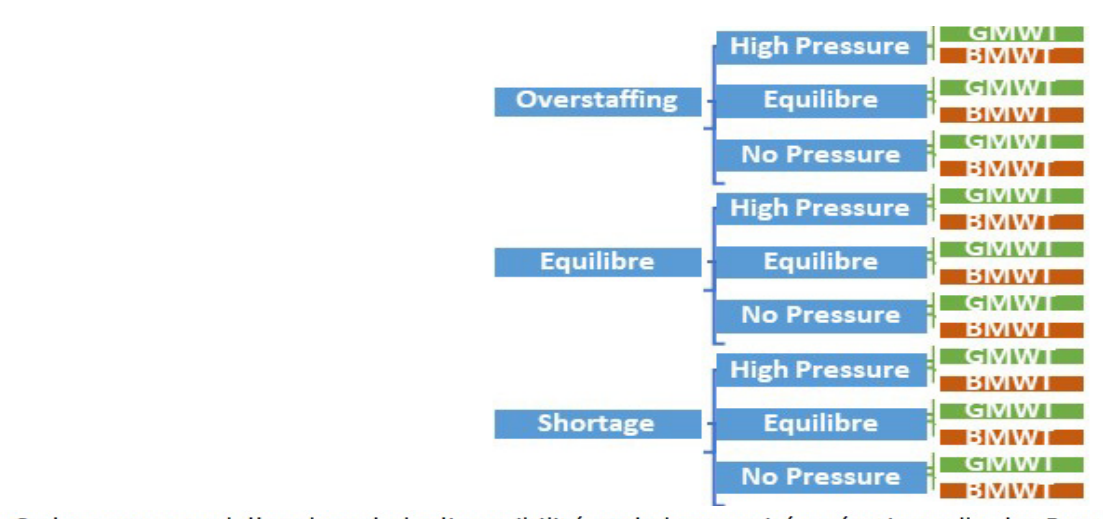

Cadre conceptuel d'analyse de la disponibilité et de la capacité opérationnelle des Ressources Humaines en Santé Qualifiées

Légende : = GM $\mid$ Good Management of Working Time and $\mathrm{BMWT} \mid=$ Bad Management of Working Time

\subsection{Ethical Aspects}

The informed consent of the actors surveyed was obtained and we ensured that anonymity and confidentiality were respected.

\section{Results}

\subsection{Characteristics of the Sample}

A total of 487 health facilities were surveyed, representing $100 \%$ of the planned health facilities. Overall, 3,870 health workers, of all categories combined, had their workloads assessed, including 1,013 Maternity Care Assistants, 729 Dispensary Care Assistants, 72 Health Action Inspectors Anaesthetists, 36 Dispensary Nurses, 38 Health Centre General Practitioners, 45 Hospital General Practitioners, 51 Surgical Specialist Practitioners, 66 Obstetrics and Gynaecology Specialist Practitioners, 9 Internist Specialist Practitioners, 37 Paediatric Specialist Practitioners, and 926 Maternity Midwives.

\subsection{Human Resources for Health Needed to Handley the Workload in Health Facilities}

In terms of HHR staffing, two indicators are estimated in this work: the number of HHR staff required to handle the overall workload and the workload in a practice setting.

\subsubsection{Staffing requirements to meet the overall workload in health facilities}

Table 1 shows the staffing requirements to handle the overall workload in the health facilities. It presents, by HHR category, the staff available at the time of the study and the staff required to handle the overall workload. By comparing the two, we have identified situations of balance, shortage, or overstaffing.

Table 1. Summary of HHR staffing to meet the overall workload in Benin's health facilities in 2018

\begin{tabular}{|c|c|c|c|c|c|}
\hline HHR Categories & $\begin{array}{c}\text { Staff } \\
\text { available (A) }\end{array}$ & $\begin{array}{c}\text { Staffing } \\
\text { requirements (B) }\end{array}$ & Discrepancies & $\begin{array}{c}\% \\
\text { (B/A) }\end{array}$ & $\begin{array}{c}\text { Nature of the } \\
\text { discrepancy }\end{array}$ \\
\hline Maternity Care Assistant & 1013 & 721 & -292 & 140 & overstaffing \\
\hline dispensary Care Assistant & 729 & 769 & 40 & 95 & Shortage \\
\hline $\begin{array}{c}\text { Inspector of Health Action } \\
\text { Anesthesiologist }\end{array}$ & 72 & 76 & 4 & 95 & Shortage \\
\hline Nurse at the dispensary & 36 & 84 & 52 & 43 & Shortage \\
\hline General Practitioner Health Centre & 38 & 38 & 0 & 100 & Equilibre \\
\hline General Practitioner Hospital & 45 & 47 & 2 & 96 & Shortage \\
\hline Specialist Practitioner - Surgery & 51 & 49 & -2 & 104 & overstaffing \\
\hline Specialist Practitioner Gynecologist & 66 & 84 & 18 & 79 & Shortage \\
\hline Specialist Practitioner - Internist & 9 & 19 & 10 & 47 & Shortage \\
\hline Specialist Practitioner - Pediatrician & 37 & 69 & 32 & 54 & Shortage \\
\hline Midwife at the maternity ward & 926 & 1652 & 726 & 56 & Shortage \\
\hline Grand Total & 3870 & 4460 & 590 & 87 & Shortage \\
\hline
\end{tabular}

Source: survey respondent data 
The assessment determined the staffing requirements to meet the overall workload in health facilities for certain categories of health professionals to cover maternal and child health Overall, a situation of overstaffing was observed among maternity care assistants, with a surplus of 292. Only one category, that of general practitioners at the health center, is in a situation of equilibrium. For this category, the number of staff available is equal to the number required to provide quality health care. There is also a shortage of nurses at the dispensary, with a gap of 52 agents to be filled. The same situation of shortage is noted at the level of midwives with a gap to be filled by 726 agents.

3.2.2. Staffing requirements for workload in health facilities by practice setting

Tables 2 presents the staffing requirements to handle the workload in the health facilities. They show the balance, shortage, and overstaffing between urban and rural areas.

Table 2. Summary of situations of balance, shortage, and overstaffing of human resources for health in Benin in urban and rural areas for the year 2018

\begin{tabular}{|c|c|c|c|c|c|c|}
\hline \multirow[b]{2}{*}{ Staff problem } & \multirow[b]{2}{*}{ Corp } & \multicolumn{3}{|c|}{ Place of assignment } & \multirow[b]{2}{*}{ \% Rural } & \multirow[b]{2}{*}{$\%$ Urban } \\
\hline & & Rural & Urban & Grand Total & & \\
\hline \multirow[t]{5}{*}{ Equilibre } & Maternity Care Assistant & & 1 & 1 & $0 \%$ & $100 \%$ \\
\hline & Dispensary Care Assistant Care Assistant & 1 & & 1 & $100 \%$ & $0 \%$ \\
\hline & Nurse at the dispensary & 3 & & 3 & $100 \%$ & $0 \%$ \\
\hline & Specialist Practitioner Gynecologist & & 7 & 7 & $0 \%$ & $100 \%$ \\
\hline & Midwife at the maternity ward & & 31 & 31 & $0 \%$ & $100 \%$ \\
\hline Total Equilibre & & 4 & 39 & 43 & & \\
\hline \multirow[t]{11}{*}{ Shortage } & Maternity Care Assistant & 93,84 & 57,43 & 151,27 & $62 \%$ & $38 \%$ \\
\hline & Dispensary Care Assistant & 222,01 & 92,46 & 314,47 & $71 \%$ & $29 \%$ \\
\hline & Inspector of Health Action Anesthesiologist & & 46,17 & 46,17 & $0 \%$ & $100 \%$ \\
\hline & Nurse at the dispensary & 419,77 & 71,28 & 491,05 & $85 \%$ & $15 \%$ \\
\hline & General Practitioner Health Centre & & 8,39 & 8,39 & $0 \%$ & $100 \%$ \\
\hline & General Practitioner Hospital & & 29,82 & 29,82 & $0 \%$ & $100 \%$ \\
\hline & Specialist Practitioner - Surgery & & 26,2 & 26,2 & $0 \%$ & $100 \%$ \\
\hline & Specialist Practitioner Gynecologist & & 45,64 & 45,64 & $0 \%$ & $100 \%$ \\
\hline & Specialist Practitioner - Internist & & 16,09 & 16,09 & $0 \%$ & $100 \%$ \\
\hline & Specialist Practitioner - Pediatrician & & 54,12 & 54,12 & $0 \%$ & $100 \%$ \\
\hline & Midwife at the maternity ward & 989,55 & 470,56 & 1460,11 & $68 \%$ & $32 \%$ \\
\hline Total Shortage & & 1725,17 & 918,16 & 2643,33 & & \\
\hline \multirow[t]{11}{*}{ Overstaffing } & Maternity Care Assistant & 185,92 & 183,89 & 369,81 & $50 \%$ & $50 \%$ \\
\hline & Dispensary Care Assistant & 212,3 & 91,84 & 304,14 & $70 \%$ & $30 \%$ \\
\hline & Inspector of Health Action Anesthesiologist & & 28,61 & 28,61 & $0 \%$ & $100 \%$ \\
\hline & Nurse at the dispensary & 156,07 & 148,36 & 304,43 & $51 \%$ & $49 \%$ \\
\hline & General Practitioner Health Centre & 0,48 & 6,02 & 6,5 & $7 \%$ & $93 \%$ \\
\hline & General Practitioner Hospital & 0 & 11,97 & 11,97 & $0 \%$ & $100 \%$ \\
\hline & Specialist Practitioner - Surgery & 0 & 13,65 & 13,65 & $0 \%$ & $100 \%$ \\
\hline & Specialist Practitioner Gynecologist & 0 & 23,72 & 23,72 & $0 \%$ & $100 \%$ \\
\hline & Specialist Practitioner - Internist & 0 & 1,22 & 1,22 & $0 \%$ & $100 \%$ \\
\hline & Specialist Practitioner - Pediatrician & 0 & 7,48 & 7,48 & $0 \%$ & $100 \%$ \\
\hline & Midwife at the maternity ward & 7,89 & 147,83 & 155,72 & $5 \%$ & $95 \%$ \\
\hline Total Overstaffing & & 562,66 & 664,59 & 1227,25 & & \\
\hline Grand Total & & 2291,83 & 1621,75 & 3913,58 & & \\
\hline
\end{tabular}


From this table, it can be observed that compared to the nurses in the dispensary, the shortage is $85 \%$ in rural areas and $15 \%$ in urban areas. For midwives, the shortage is $68 \%$ in rural areas and $32 \%$ in urban areas.

Observing the table reveals a situation of overstaffing of midwives at the maternity hospital estimated at $95 \%$ in urban areas and 5\% in rural areas. Similarly, the situation of overstaffing is observed among doctors in health centers to be $93 \%$ in urban areas and $7 \%$ in rural areas.

\subsection{Distribution of HHR Working Time in the Public Sector}

The results obtained on the basis of the distribution of working time will be presented and analyzed globally and according to the place of assignment.

\subsubsection{Overall distribution of HHR working time in the public sector}

Table 3 summarizes the use of HHR working time.
Three groups of activities were measured in 2018: main, support, and additional activities.

Overall, the minimum working time devoted to the main activities is $13.42 \%$ carried out by general practitioners at the health facility and the maximum is $67.12 \%$ carried out by midwives. The minimum time devoted to support activities is $27.45 \%$ carried out by midwives and the maximum time devoted to support activities is $84.07 \%$, carried out by general practitioners working in health facility. The minimum time devoted to additional activities is $0.78 \%$ carried out by maternity care assistants and the maximum time is $14.25 \%$ carried out by nurses at the dispensary.

3.3.2. Distribution of HHR working time in the public sector by mid-year in 2018

Tables $4 \mathrm{a}$ and $4 \mathrm{~b}$ present the results of the distribution of HHR working time in the public sector in Benin, according to the criterion of activity and mid-year in 2018 .

Table 3. Distribution of HHR working time by activity groups in the public sector in Benin in 2018

\begin{tabular}{|c|c|c|c|c|c|c|c|c|}
\hline \multirow{2}{*}{ Corps des RHS } & \multicolumn{9}{|c|}{ Activity Groups } \\
\cline { 2 - 9 } & Main Activities & Support activities & \multicolumn{2}{|c|}{$\begin{array}{c}\text { Additional } \\
\text { Activities }\end{array}$} & \multicolumn{2}{c|}{ Total } \\
\cline { 2 - 9 } & $\begin{array}{c}\text { Working } \\
\text { time }\end{array}$ & $\begin{array}{c}\text { Weight } \\
(\%)\end{array}$ & $\begin{array}{c}\text { Working } \\
\text { time }\end{array}$ & $\begin{array}{c}\text { Weight } \\
(\%)\end{array}$ & $\begin{array}{c}\text { Working } \\
\text { time }\end{array}$ & $\begin{array}{c}\text { Weight } \\
(\%)\end{array}$ & $\begin{array}{c}\text { Working } \\
\text { time }\end{array}$ & $\begin{array}{c}\text { Weight } \\
(\%)\end{array}$ \\
\hline Maternity Care Assistant & 319,59 & 43,83 & 403,9 & 55,39 & 5,7 & 0,78 & 729,19 & 100 \\
\hline Dispensary Care Assistant & 328,55 & 29,4 & 715,68 & 64,03 & 73,41 & 6,57 & 1117,64 & 100 \\
\hline Inspector of Health Action Anesthesiologist & 62,98 & 60,69 & 39,5 & 38,06 & 1,3 & 1,25 & 103,78 & 100 \\
\hline Nurse at the dispensary & 516,05 & 42,12 & 534,48 & 43,63 & 174,52 & 14,25 & 1225,05 & 100 \\
\hline General Practitioner Health Centre & 9,53 & 13,42 & 59,69 & 84,07 & 1,78 & 2,51 & 71 & 100 \\
\hline General Practitioner Hospital & 27,45 & 36 & 46,82 & 61,4 & 1,98 & 2,6 & 76,25 & 100 \\
\hline Specialist Practitioner - Surgery & 27,27 & 36,49 & 45,09 & 60,33 & 2,38 & 3,18 & 74,74 & 100 \\
\hline Specialist Practitioner Gynecologist & 55,01 & 51,16 & 50,77 & 47,22 & 1,74 & 1,62 & 107,52 & 100 \\
\hline Specialist Practitioner - Internist & 12,17 & 35,6 & 21,23 & 62,09 & 0,79 & 2,31 & 34,19 & 100 \\
\hline Specialist Practitioner - Pediatrician & 43,48 & 48,48 & 44,79 & 49,94 & 1,42 & 1,58 & 89,69 & 100 \\
\hline Midwife at the maternity ward & 1318,67 & 67,12 & 539,31 & 27,45 & 106,64 & 5,43 & 1964,62 & 100 \\
\hline
\end{tabular}

Source: survey respondent data 
Table 4a. Breakdown of HHR working time in the public health sector in Benin according to activity criteria and mid-year in 2018

\begin{tabular}{|c|c|c|c|c|c|c|}
\hline \multirow[b]{2}{*}{ HHR Corps } & \multirow[b]{2}{*}{ Activity Groups } & \multicolumn{5}{|c|}{ Exercise environment } \\
\hline & & Rural & Urban & Total general & \% Rural & \% Urban \\
\hline \multirow{3}{*}{ Maternity Care Assistant } & Main Activities & 203,02 & 116,57 & 319,59 & $39 \%$ & $57 \%$ \\
\hline & Additional Activities & 4,57 & 1,13 & 5,7 & $1 \%$ & $0 \%$ \\
\hline & Support activities & 316,81 & 87,09 & 403,9 & $60 \%$ & $43 \%$ \\
\hline Total Maternity Care Assistants & & 524,4 & 204,79 & 729,19 & $72 \%$ & $28 \%$ \\
\hline \multirow{3}{*}{ Maternity Care Assistant at the Health Facility } & Main Activities & 57,41 & 8,99 & 66,4 & $51 \%$ & $63 \%$ \\
\hline & Additional Activities & 0,81 & 0,13 & 0,94 & $1 \%$ & $1 \%$ \\
\hline & Support activities & 55,04 & 5,2 & 60,24 & $49 \%$ & $36 \%$ \\
\hline Total Maternity Care Assistants at the Health Facility & & 113,26 & 14,32 & 127,58 & & \\
\hline \multirow{3}{*}{ Maternity Care Assistant at the Hospital } & Main Activities & & 92,74 & 92,74 & & $73 \%$ \\
\hline & Additional Activities & & 1,75 & 1,75 & & $1 \%$ \\
\hline & Support activities & & 32,68 & 32,68 & & $26 \%$ \\
\hline Total Maternity Care Assistants at the Hospital & & & 127,17 & 127,17 & & \\
\hline \multirow{3}{*}{ Dispensary Care Assistant } & Main Activities & 228,99 & 99,56 & 328,55 & $27 \%$ & $39 \%$ \\
\hline & Additional Activities & 58,41 & 15 & 73,41 & $7 \%$ & $6 \%$ \\
\hline & Support activities & 574,63 & 141,05 & 715,68 & $67 \%$ & $55 \%$ \\
\hline Total dispensary Care Assistants & & 862,03 & 255,61 & 1117,64 & & \\
\hline \multirow{3}{*}{ Inspector of Health Action Anesthesiologist } & Main Activities & & 62,98 & 62,98 & & $63 \%$ \\
\hline & Additional Activities & 0 & 1,3 & 1,3 & & $1 \%$ \\
\hline & Support activities & 4,4 & 35,1 & 39,5 & & $35 \%$ \\
\hline Total Inspectors of Health Action Anesthesiologist & & 4,4 & 99,38 & 103,78 & & \\
\hline \multirow{3}{*}{ Nurses at the dispensary } & Main Activities & 361,77 & 154,28 & 516,05 & $39 \%$ & $52 \%$ \\
\hline & Additional Activities & 135,38 & 39,14 & 174,52 & $15 \%$ & $13 \%$ \\
\hline & Support activities & 431,94 & 102,54 & 534,48 & $46 \%$ & $35 \%$ \\
\hline Total Nurses at the Dispensary & & 929,09 & 295,96 & 1225,05 & & \\
\hline \multirow{3}{*}{ General Practitioners of the Health Center } & Main Activities & 0,23 & 9,3 & 9,53 & $2 \%$ & $16 \%$ \\
\hline & Additional Activities & 0,17 & 1,61 & 1,78 & $1 \%$ & $3 \%$ \\
\hline & Support activities & 13,39 & 46,3 & 59,69 & $97 \%$ & $81 \%$ \\
\hline Total General Practitioner in the Health Center & & 13,79 & 57,21 & 71 & & \\
\hline \multirow{3}{*}{ General Practitioners in Hospitals } & Main Activities & & 27,45 & 27,45 & & $36 \%$ \\
\hline & Additional Activities & & 1,98 & 1,98 & & $3 \%$ \\
\hline & Support activities & & 46,82 & 46,82 & & $61 \%$ \\
\hline Total General Practitioners in Hospitals & & & 76,25 & 76,25 & & \\
\hline
\end{tabular}

Source: survey respondent data 
Table 4b. Breakdown of HHR working hours in the public health sector in Benin according to activity criteria and the environment of affection in 2018

\begin{tabular}{|c|c|c|c|c|c|c|}
\hline \multirow[b]{2}{*}{ HHR Corps } & \multirow[b]{2}{*}{ Activity Groups } & \multicolumn{5}{|c|}{ Exercise environment } \\
\hline & & Rural & Urban & Total general & $\%$ Rural & $\%$ Urban \\
\hline \multirow{3}{*}{ Specialist Practitioner - Surgery } & Main Activities & & 27,27 & 27,27 & & $39 \%$ \\
\hline & Additional Activities & 0 & 2,38 & 2,38 & & $3 \%$ \\
\hline & Support activities & 5,32 & 39,77 & 45,09 & & $57 \%$ \\
\hline Total Specialist Practitioners - Surgery & & 5,32 & 69,42 & 74,74 & & \\
\hline \multirow{3}{*}{ Specialist Practitioner Gynecologist } & Main Activities & & 55,01 & 55,01 & & $54 \%$ \\
\hline & Additional Activities & 0 & 1,74 & 1,74 & & $2 \%$ \\
\hline & Support activities & 5,32 & 45,45 & 50,77 & & $44 \%$ \\
\hline Total Specialist Practitioners Gynecologist & & 5,32 & 102,2 & 107,52 & & \\
\hline \multirow{3}{*}{ Specialist Practitioner - Internist } & Main Activities & & 12,17 & 12,17 & & $42 \%$ \\
\hline & Additional Activities & 0 & 0,79 & 0,79 & & $3 \%$ \\
\hline & Support activities & 5,32 & 15,91 & 21,23 & & $55 \%$ \\
\hline Total Specialist Practitioners - Internist & & 5,32 & 28,87 & 34,19 & & \\
\hline \multirow{3}{*}{ Specialist Practitioner - Pediatrician } & Main Activities & & 43,48 & 43,48 & & $52 \%$ \\
\hline & Additional Activities & 0 & 1,42 & 1,42 & & $2 \%$ \\
\hline & Support activities & 6,69 & 38,1 & 44,79 & & $46 \%$ \\
\hline Total Specialist Practitioners - Pediatrician & & 6,69 & 83 & 89,69 & & \\
\hline \multirow{3}{*}{ Midwives in the maternity ward } & Main Activities & 818,15 & 500,52 & 1318,67 & $64 \%$ & $73 \%$ \\
\hline & Additional Activities & 55,19 & 51,45 & 106,64 & $4 \%$ & $7 \%$ \\
\hline & Support activities & 404,63 & 134,68 & 539,31 & $32 \%$ & $20 \%$ \\
\hline Total Midwives in the maternity ward & & 1277,97 & 686,65 & 1964,62 & & \\
\hline
\end{tabular}

Source: survey respondent data 
According to Tables $4 \mathrm{a}$ and $4 \mathrm{~b}$, nurses working in rural dispensaries devote $39 \%$ of their working time to main activities, $15 \%$ to additional activities and $46 \%$ to support activities. Nurses working in urban dispensaries devote $52 \%$ of their work time to main activities, $13 \%$ to additional activities, and $35 \%$ to support activities. The midwives practicing maternity in rural areas devotes $64 \%$ to main activities, $4 \%$ to additional activities, and $32 \%$ to support activities. Midwives who practice maternity in urban areas devote $73 \%$ of their work time to main activities, $7 \%$ to additional activities, and 20\% to support activities.

\subsection{Workload Pressure}

3.4.1. HHR workload pressures in health facilities
Table 5 presents the results of the WISN ratios by HHR category and subsequent interpretations. The WISN ratio is the ratio of required to the available workforce. It is used to assess workload pressure.

Overall, nine HHR categories are below the equilibrium situation while two are above the equilibrium. The WISN ratios calculated from the HHR categories show that internist specialists have a ratio of 0.47 and maternity care assistant have a ratio of 1.40 .

\subsubsection{Workload Pressure on HHR in Health Facilities by Workplace Setting}

Table 6 presents the results of the crossover of work pressure by HHR category and by practice setting.

Table 5. Presentation of the WISN ratios of certain categories of HHR in Benin's public sector in 2018

\begin{tabular}{|l|c|c|c|c|}
\hline Categories & Staff available & $\begin{array}{c}\text { Staffing } \\
\text { requirements }\end{array}$ & WISN Ratio & $\begin{array}{c}\text { Interpreting the WISN } \\
\text { ratio }\end{array}$ \\
\hline Maternity Care Assistant & 1013 & 721 & 1,40 & No pressure \\
\hline Dispensary Care Assistant & 729 & 769 & 0,95 & High Pressure \\
\hline $\begin{array}{l}\text { Inspector of Health Action } \\
\text { Anesthesiologist }\end{array}$ & 72 & 76 & 0,95 & High Pressure \\
\hline Nurse at the dispensary & 884 & 936 & 0,94 & High Pressure \\
\hline General Practitioner Health Centre & 38 & 38 & 1,00 & Equilibre \\
\hline General Practitioner Hospital & 45 & 47 & 0,96 & High Pressure \\
\hline Specialist Practitioner - Surgery & 51 & 49 & 1,04 & No pressure \\
\hline Specialist Practitioner Gynecologist & 66 & 84 & 0,79 & High Pressure \\
\hline Specialist Practitioner - Internist & 9 & 19 & 0,47 & High Pressure \\
\hline Specialist Practitioner - Pediatrician & 37 & 69 & 0,54 & High Pressure \\
\hline Midwife at the maternity ward & 926 & $\mathbf{3 8 5 2}$ & 0,56 & High Pressure \\
\hline Total general & $\mathbf{3 8 6 0}$ & $\mathbf{0 , 8 7}$ & High Pressure \\
\hline
\end{tabular}

Source: survey respondent data 
Table 6. Presentation of WISN ratios by the environment and their interpretations

\begin{tabular}{|c|c|c|c|c|c|c|c|c|c|c|}
\hline \multirow{3}{*}{ Corps } & \multicolumn{9}{|c|}{ Environment } & \\
\hline & \multicolumn{5}{|c|}{ Rural } & \multicolumn{5}{|c|}{ Urban } \\
\hline & $\begin{array}{l}\text { Available } \\
\text { manpower }\end{array}$ & $\begin{array}{c}\text { Total } \\
\text { required } \\
\text { workforce }\end{array}$ & $\begin{array}{l}\text { Difference/ } \\
\text { excess }\end{array}$ & $\begin{array}{l}\text { Ratio } \\
\text { WISN }\end{array}$ & $\begin{array}{l}\text { interpretation of } \\
\text { the WISN ratio }\end{array}$ & $\begin{array}{l}\text { Available } \\
\text { manpower }\end{array}$ & $\begin{array}{c}\text { Total required } \\
\text { workforce }\end{array}$ & $\begin{array}{c}\text { Difference/ } \\
\text { excess }\end{array}$ & $\begin{array}{l}\text { Ratio } \\
\text { WISN }\end{array}$ & $\begin{array}{l}\text { interpretation of the } \\
\text { WISN ratio }\end{array}$ \\
\hline Maternity Care Assistant & 512 & 443 & 69 & 1,16 & No pressure & 501 & 278 & 223 & 1,80 & No pressure \\
\hline Dispensary Care Assistant & 504 & 562 & -58 & 0,90 & High Pressure & 225 & 207 & 18 & 1,09 & No pressure \\
\hline Inspector of Health Action Anesthesiologist & 0 & 0 & 0 & & & 72 & 76 & -4 & 0,95 & High Pressure \\
\hline Nurse at the dispensary & 475 & 696 & -221 & 0,68 & High Pressure & 409 & 240 & 169 & 1,70 & No pressure \\
\hline General Practitioner Health Centre & 5 & 4 & 1 & 1,25 & No pressure & 33 & 34 & -1 & 0,97 & High Pressure \\
\hline General Practitioner Hospital & & & 0 & & & 45 & 47 & -2 & 0,96 & High Pressure \\
\hline Specialist Practitioner - Surgery & 0 & 0 & 0 & & & 51 & 49 & 2 & 1,04 & No pressure \\
\hline Specialist Practitioner Gynecologist & 0 & 0 & 0 & & & 66 & 84 & -18 & 0,78 & High Pressure \\
\hline Specialist Practitioner - Internist & 0 & 0 & 0 & & & 9 & 19 & -10 & 0,47 & High Pressure \\
\hline Specialist Practitioner - Pediatrician & 0 & 0 & 0 & & & 37 & 69 & -32 & 0,54 & High Pressure \\
\hline Midwife at the maternity ward & 318 & 1017 & -699 & 0,31 & High Pressure & 608 & 635 & -27 & 0,96 & High Pressure \\
\hline Total général & 1814 & 2722 & -908 & 0,67 & High Pressure & 2056 & 1738 & 318 & 1,18 & No pressure \\
\hline
\end{tabular}

The results indicate that the WISN ratio of the nurses practicing in a rural area is 0.68 and that in an urban area is 1.70 . The WISN ratio for the rural midwife is 0.31 and the urban midwife is 0.96 . 


\section{Discussion}

The discussion will focus briefly on the achievement of objectives, the quality and reliability of the results, and the comparison of results with previous works.

This study was an opportunity to calculate the number of health workers per category of health workers needed to cover the workload in Benin's public health facilities. It also made it possible to determine the occupations of the human resources in relation to the three categories of activities, i.e. main, support, and additional activities, in order to deduce the pressure of the workload on the human resources in Benin's health facilities.

The data used for this research were obtained from primary sources, such as registries that may be subjected to transcription bias. However, these errors are minimized by transcription in DHIS2, supervision, and validation of the health statistics directory. Moreover, the quality control of the DHIS2 data allows us to note that any biases cannot be allowed to compromise the quality and validity of the data used.

A comparison of the results of this study, with those of the literature review mentioned above, shows that the study is relevant. It leads to a conclusion that the use of the WISN tool is an opportunity to make a good specification of workload and needs, better projections in terms of planning and deployment of Qualified Health Workers (QHW).

\subsection{Staffing Requirements for the Workload}

The number of staff required to cover the workload related to the demand for care in Benin, two main observations emerge from the application of the WISN method. First, the corps of health care assistants working in maternity wards is highly overstaffed, with more than 292 surplus staff in the country. Second, all the other Health Workers corps studied are in shortage. This overstaffing of nurses' assistants is linked to the recruitment without standards from 1997 to 2008. At that time, with debt remission to the Heavily Indebted Poor Countries, Benin injected the funds from the debt remission into the social sectors (health and education). The Ministry of Health, therefore, decided to recruit Health Workers. This initiative, which should make it possible to provide health facilities with qualified Health Workers, has unfortunately been diverted from its original purpose to serve partisan and courtesan interests, with the recruitment of a large number of nurses' assistants as a result. The shortage situation is much greater for all other Health Workers bodies studied. The corps of midwives practicing in maternity wards is in a shortage situation with a need for 726 midwives; the corps of nurses practicing in a dispensary is in a shortage situation with a need for 52 nurses; the corps of paediatricians is in a shortage situation with a need for 32 paediatricians. This observed shortage is induced by the mismatch between Health Workers training and recruitment. There are two medical schools and two training institutes for midwives and nurses in the country, and their QHW production capacity is below the countrys' public and private needs.

A reading of the results, according to the agents' practice environment (urban and rural), shows that the shortage is more pronounced in rural than in urban areas. Apart from nurses who work in dispensaries and midwives who work in maternity wards, the other QHW bodies are almost non-existent in rural areas. This can be explained by the pyramid structure of the health system in place in the country. Because of this structure, the first levels of contact are occupied by nurses and midwives. This gives rise to discrimination in favor of the urban environment, where overstaffing is observed. Recourse to the code of ethics for nurses, inspired by French law, specifies that the nurse applies and respects the protocols drawn up by the doctor and provided by the regulatory provisions.

The rural nurse is alone in meeting the demand for care for a whole year, without the supervision and guidance of a doctor, even though this is provided for in the regulations. As a result, there is an inequity in response to the demand for care. Through the work carried out in Benin in 2018, the authors, after noting the existence of inequity in the distribution of Health Workers, asked themselves what type of equity should be used in the distribution of Health Workers: vertical equity and/or horizontal equity [24]. Other research work has also emphasized the shift from the analysis of inequalities in health to that of inequalities in health opportunities, which better reflects the notion of health equity [25]. In Benin, this high concentration of Health Workers in urban areas is maintained by the failure to comply with the laws and regulations in force. Even the recruitment of new staff in 2014 was unable to keep staff in their posts.

We hope that the reform measures regarding the drafting of a law on the organization of the health system (which never existed), the creation of a regulatory authority for the health system, the departmentalization of recruitment in order to reduce the inequity between rural and urban areas (which could not be done without the law), and a review of the mechanism for recruitment, career management and working hours of health workers recommended by the Government in place since 2016 will provide an effective solution to these shortcomings.

To circumvent this inequity, Namaganda G., \& al. recommended the use of WISN for a fair match between workload and human resources [12]. This observation reopened the debate on the issue of health equity addressed by Sossou GA \& al. [24] who asked "what is equity in the distribution of the health workforce? ». Better still, they insist on how the distribution of personnel should be done, according to which type of equity: vertical equity and/or horizontal equity? then how the concentration of Health Workers in an urban facility to the detriment of a rural facility is inequitable? In their work, Rochaix L. \& al. 
concluded that there is no universal answer to characterize equity, but rather that the philosophical framework and values of the society concerned must be taken into account [25].

According to article 8 of the constitution of 11 December 1990 amended by Law 2019-40 of 1 November 2019 , the right to health in Bénin is a fundamental right and the vision of the national health policy that was translated into a strategy in the national health development plan (2018-2022) further reinforces this. It was, therefore, believed that it is important to remember that in Benin, in structuring the supply of health care, it is necessary to act through both vertical and horizontal equity and to go beyond. Because of the negative externality of disease and the influence of welfare on economic growth, health equity should be seen as a state's ability to develop and enforce laws and regulations for UHC. The observation that the concentration of QHW in urban areas to the detriment of rural areas, while the workload does not impose it, falls into constitutional illegality and the silence of the central government reflects the weakness of its institutions. It is on the strength of these inadequacies that $[26,27]$ concluded that workload must be taken into account to meet human resource needs.

The direct consequence of inequity in the distribution of Health Workers is the long waiting time for users of the system and inefficiency. Approaching this question from the angle proposed in previous studies [29, 30] have concluded that there are technical and allocative efficiencies in the allocation of QHHRs. According to the authors, technical efficiency refers to the ability of a health system to produce a better outcome with the same resources, and allocative efficiency refers to the ability of a system to direct its resources in an optimal way. Over-staffing situations are unproductive because there is a mismatch between the workload and the human resources allocated. There is, therefore, technical inefficiency at this level. Deploying health professionals in a health care facility, when the workload does not require it, is also an allocative inefficiency. This inefficiency is twofold because salaries are paid unduly and there are poorly deployed staff, a conclusion that [30] has been reached in a previous study. The shortage situations observed in some places generate sources of both technical and allocative inefficiency. Technical inefficiency is observed at this level in the sense that the work pressure caused by understaffing will have a negative impact on the quality of care for the beneficiaries of health services. The situation of shortage in rural areas leads to poor access to health services despite the high demand [30]. It is, therefore, inferred that both types of inefficiency are present in this study.

However, Paul et al. noted in their work that there is no clear-cut definition of equity in the literature review, but that equity appears to be the balance pursued by universal health coverage, and as soon as health is recognized as a fundamental right, the search for this balance is imposed on the State [31]. The WHO World Health Report 2008 insists on the need to implement the reforms pertaining to UHC to improve health equity [32].

\subsection{Distribution of HHR Working Time in the Public Health Sector}

On the issue of staff occupation, the study found that out of the eleven HHR corps that were the subject of this study, three corps devote more than $50 \%$ of their working time to core activities. These are the corps of gynaecological practitioners, midwives working in maternity wards, and IAS-anaesthetists. However, health care assistants in dispensaries, general practitioners in health centers, general practitioners in hospitals, specialist surgeon practitioners, and specialist internist practitioners devote more than $60 \%$ of their working time to support activities. The presence or absence of general practitioners influences the workload of nurses and midwives who work alongside doctors, as highlighted in the work on the analysis of efficiency of health expenditure carried out in Benin in 2018, where the authors estimate that the void created by the absence of doctors is filled by the overload of nurses and midwives [30]. In the Beninese context, it is important to make further research to look for the impact of the time spent by medical professionals on their main activities on the quality of care of beneficiaries, particularly on the health of the mother and child. The high maternal, neonatal, and infant mortality rate in the country supports the assertion that most of the main activities are carried out by health care workers on behalf of midwives and nurses.

\subsection{Workload Pressure}

On the subject of work pressure, the study revealed that apart from the maternity care assistants, the general practitioners in the health facility and the specialist surgical practitioners have no work pressure. The work pressure is very high among the nursing in dispensaries, the inspector of health action anesthesiologist, general practitioners in hospitals, specialist practitioners in gynaecology and obstetrics, specialist practitioners in internships, specialist practitioners in paediatrics and midwives in maternity wards. An analysis of the results by practice setting shows that work pressure is higher in rural than urban settings for the most common rural HHR bodies. In view of all the above, it can be deduced that Benin's health system at the current stage is fragile. A comparison of these results with the work of Zongo \& al. and Tichenor \& al. [33, 34] confirms this fragility. Better in the context of health system reform, the diagnosis of the poor performance of the health system in Benin highlights a certain number of factors that further confirm the fragility of the system [4]. It will, therefore, be necessary to carry out far-reaching reforms to strengthen Benin's health system by optimizing 
management and reducing low productivity, separating procurement from the supply, in order to achieve significant efficiency gains; this is what Ruff \& al. recommend in their work carried out in 2011 in South Africa for the South African health system in order to improve its productivity and responsiveness [35].

A study of Angola, Ethiopia, Mozambique, Rwanda, and Eritrea has shown that reducing real mortality requires action on three fronts: decentralization of health systems, innovation, and health financing [36].

High workload pressure is a source of overexploitation of the human resources involved and affects their own health and the quality of the health services and care they provide. Thus, with the introduction of the health insurance component of the Assurance for $\mathrm{ARCH}$, the financial barriers to the use of health services would be removed. In order to contain the high demand and the sustainability of the measures that will be taken, it will be necessary to work on the production, recruitment, planning, and retention of HHR in their posts. It will also be necessary to ensure a balance between the workload and deployment of QHHRs in health facilities across the country and between services within the same health facility. These precautionary measures are necessary to avoid poor performance achieved in Ethiopia in the wake of the Business Process Reengineering reform [36]. The same caution is recommended with regard to the work of Okuonzi S.A and Esteves, R.J [27, 37].

\section{Conclusions}

The availability of qualified human resources for health is one of the fundamental pillars, indispensable to each country in its progress towards the UHC. This study revealed that the logic of defining and planning Health Workers needs using the WISN tool is very relevant. It also highlighted that the additional Health Workers made available to the health system and the readjustments necessary to have the workforce in line with the workload developed in the country. It has been observed that both technical and allocation inefficiencies are generated by situations of overstaffing, shortages, overload, and poor use of the working time of health professionals. The study also revealed that general practitioners at the health center devote more time to support activities to the detriment of the main activities, whereas medical acts are their responsibility. This situation needs to be studied in more detail in order to see to what proportion the nurse and the midwife work instead of the health center doctor.

The implementation of the reforms undertaken by the government and the strengthening of the mechanisms for regulating the health system should make it possible to optimize both human and financial resources and the quality of care with a view to significantly reduce morbidity and mortality among the population, in general, and among mothers and children in particular. In its current form, the health system is not in a position to receive a large flow that will be drained by the implementation of the UHC at a national level. This will require sustained support for ongoing reforms and greater investment in the production, recruitment, and retention of QHW.

\section{Conflict of Interest}

The authors do not declare any conflict of interest.

\section{Acknowledgements}

The authors would like to thank the authorities of the Ministry of Health at the central, intermediate, and peripheral levels for their participation in this study.

\section{REFERENCES}

[1] National Institute of Statistics and Economic Analysis, Demographic and Health Survey in Benin 2017-2018, Cotonou, Bénin et Rockville, Maryland, USA: INSAE et ICF, 2019: p. 629. available, https://academic.oup.com/hea pol/article-abstract/5/2/167/633714?redirectedFrom=fulltex

[2] Ministry of Health Benin Republic, WHO, Health Human Resources Labour Market Study. MoH Benin, WHO, 2019: p. 112.

[3] Ministry of Health Benin Republic, WHO., Assessing the availability, operational capacity of health services and patient satisfaction (SARA+ 2018), MoH Benin, WHO 2019: p. 208.

[4] Technical commission in charge of reforms in the health sector in Benin Republic, Report of the Committee, 2017.

[5] Cuellar C., C.A., Harris A., Korynski P., Evaluation of the private health sector in Benin Republic. Bethesda, MD, Strengthening Health Outcomes through the Private Sector Project, Abt Associates Inc. 2013: p. 106. available, www.shopsproject.org

[6] Ministry in charge of Social Protection, insurance project document for the strengthening of human capital (ARCH)., Protecting the poor and reducing vulnerability 2017.

[7] Shipp P.J., Workload Indicators of Staffing Need (WISN): a manual for implementation Prepared for the World Health Organization by Shipp Peter J. WHO/HRB/98.2, 1998: p. $1-165$.

[8] Acharya D., D.B., Wagle B.P, Factors Associated to the Enrollment in Health Insurance: An Experience from Selected Districts of Nepal Canadian Center of Science and Education 2019. 15(2): p. 90.

[9] WHO, Health Workforce Needs in Relation to Workload Indicators (WISNs): the experience of implementation in 
several countries. WHO Human Resources for Health Observer 2017. 15: p. 37.

[10] Hagopian, A., Mohanty, MK., Das, A., House, PJ., Applying WHO's 'workforce indicators of staffing need' (WISN) method to calculate the health worker requirements for India's maternal and child health service guarantees in Orissa State. Health Policy Plan, 2012. 27(1): p. 11-8.

[11] Shivam, S., et al., Nursing personnel planning for rural hospitals in Burdwan District, West Bengal, India, using workload indicators of staffing needs. J Health Popul Nutr, 2014. 32(4): p. 658-64.

[12] Namaganda, G., et al., Making the transition to workload-based staffing: using the Workload Indicators of Staffing Need method in Uganda. Hum Resour Health, 2015. 13: p. 89 .

[13] Nyamtema, A., Urassa, DP., Massawe, S, Massawe, A, Lindmark G.Van Roosmalen J., Staffing needs for quality perinatal care in Tanzania. Afr J Reprod Health, 2008. 12(3): p. 113-24.

[14] Owino W., O.L., Ochieng M., Ouma E., Chege E., Sang C., Baseline and workload indicator assessment for commuty health workforce: a Case of Selected Community Units in Nyanza and Coast Regions. Capacity Kenya 2013: p. 1-68.

[15] Antarou, L., Ridde, V., Kouanda, S., Queuille, L., [Health staff workload in a context of user fees exemption policy for health care in Burkina Faso and Niger]. Bull Soc Pathol Exot, 2013. 106(4): p. 264-271.

[16] Yin, D., Yin, T., Yang, H., Xin, Q., Wang, L., Li, N., Ding, $\mathrm{X}$. Chen, B., An economic-research-based approach to calculate community health-staffing requirements in Xicheng District, Beijing. Hum Resour Health, 2016. 14(1): p. 70.

[17] Kolehmainen-Aitken RL, Shipp P, «Indicateurs des besoins en personnel»: évaluer le personnel de santé et l'équité en Papouasie-Nouvelle-Guinée. Health Policy and Planning, 1990. 5(2): p. 167

[18] Bonfim D, L.A., Leal AE, Fugulin FMT, Gaidzinski RR, Application of the Workload Indicators of Staffing Need method to predict nursing human resources at a Family. Health ServiceRev. Latino-Am. Enfermagem, 2016. 24(e2683)

[19] Govule P, M.J., Katongole SP, Maniple E, Nanyingi M, Robert Anguyo DDM Onzima, Application of Workload Indicators of Staffing Needs (WISN) in Determining Health Workers' Requirements for Mityana General Hospital, Uganda International Journal of Public Health Research 2015. 3(5): p. 254-263

[20] Govule P, Mugisha JF, Katongole SP, Maniple E, Nanyingi M, Robert Anguyo DDM Onzima, Using the Workload Indicator for Staffing Needs methodology to assess work pressurer among the nursing staff of Lacor Hospital. 2008. volume 6(1): p. 1-15.

[21] McQuide, P.A., R.L. Kolehmainen-Aitken, and N. Forster, Applying the workload indicators of staffing need (WISN) method in Namibia: challenges and implications for human resources for health policy. Hum Resour Health, 2013. 11: p. 64.

[22] Ministry of Health of Benin, Yearbook of Health Statistics
2018. p. 224.

[23] Thaddeus S., M.D., Too far to walk: maternal mortality in context. Social Science \& medicine, 1994. 38(8): p. 1091-1110.

[24] Ministry of Health of Benin Republic, WHO., Sossou GA, Fantodji M, Elaboration of the strategy for endowing public health facilities with human resources qualified with a view to the implementation of Insurance for Human Capital Strengthening (ARCH). 2018: p. 1-73.

[25] Rochaix L., Tubeuf S., "Measures of Health Equity" Ethical Foundations and Implications. Economic Review, 2009. 2(60): p. 325-344.

[26] Shivam S., Roy R.N., Dasgupta, S., Bhattacharyya, K.D, Misra, R. N, Roy S., Indranil S.., Nursing Personnel Planning for Rural Hospitals in Burdwan District, West Bengal, India, Using Workload Indicators of Staffing Needs. J HEALTH POPUL NUTR 2014. 32(4): p. 658-664

[27] Okuonzi S.A., Learn from the Failure of Health Reform in Uganda. BMJ, 2004. 329(7475): p. 1173-1175. doi doi: 10.1136 / bmj.329.7475.1173.

[28] Mugo N.S., Dibley M.J, Damundu E.Y, Alam A., "The system here isn't on patients' side"- perspectives of women and men on the barriers to accessing and utilizing maternal healthcare services in South Sudan. BMC Health Serv Res, 2018. 18(1): p. 10., doi 10.1186/s12913-017-2788-9

[29] Mathonnat J., Analytical framework for the improvement of human resources for health in relation to the problem of budget space in selected WAEMU countries. Study at the request of WHO, Health Workforce Department, Genève, Juillet 2018. 2018

[30] Ministry of Health of Benin Republic, WHO, Kouakou A., Sossou, G.A., Tapsoba Y., Fantodji M.K Analysis of the efficiency of human resources for health in relation to the budgetary space for health in Benin. Study carried out at the request of WHO, Health Workforce Department, Genève, Août 2019. 2019

[31] Elisabeth Paul, C.D., Oriane Bodson, N'koué Emmanuel Sambiéni, Ibrahima Thiam, Marc Bourgeois, Valéry Ridde and Fabienne Fecher, How is equity approached in universal health coverage? An analysis of global and country policy documents in Benin and Senegal. International Journal for Equity in Health, 2019. 18(195).

[32] WHO, World Health Report 2008: Primary Health Care Now More Than Ever. 2008. available at:https://www.paho.org/hq/dmdocuments/2010/APS_Rapp ort_sur_la_sante_dans_le_monde-2008.pdf.33.

[33] Zongo A., KiendrébéogoJ. A., Van de Put W., Meessen B., health system and fragility in Francophone Africa. 2019: p. 1. available onhttp://www.healthfinancingafrica.org/home/sys temes-de-sante-et-fragilite-en-afrique-francophone, accessed 12/02/2020

[34] Tichenor M., Sridhar D., Universal health coverage, health systems strengthening, and the World Bank. BMJ, 2017. doi: 10.1136/bmj.j3347.

[35] Ruff B., Mzimba M., Hendrie S., Broomberg J., Reflections on health-care reforms in South Africa. J Public Health Policy, 2011. 32(1): p. S184-92. doi 10.1057/jphp.2011.31 
[36] Manyazewal T., Matlakala MC, Implimentation health care reform: implication for the performance of central Ethiopia public hospitals. J Glob Health 2018. 8 (1). doi: 10.7189 / jogh.08.010403
[37] Esteves, R.J., The quest for equity in Latin America: a comparative analysis of the health care reforms in Brazil and Colombia. Int J Equity Health, 2012. 11: p. 6. doi 10.1186/1475-9276-11-6. 